\title{
Serum Glial Fibrillary Acidic Protein as a Specific Marker for Necrotizing Meningoencephalitis in Pug Dogs
}

\author{
Hizuru MIYAKE ${ }^{1)}$, Akiko INOUE ${ }^{1)}$, Miho TANAKA ${ }^{1)}$ and Naoaki MATSUKI ${ }^{1) *}$ \\ ${ }^{1)}$ Department of Veterinary Clinical Pathobiology, Graduate School of Agricultural and Life Sciences, The University of Tokyo, 1-1-1 \\ Yayoi, Bunkyo-ku, Tokyo 113-8657, Japan
}

(Received 17 May 2013/Accepted 1 July 2013/Published online in J-STAGE 12 July 2013)

ABSTRACT. To evaluate the ability of serum glial fibrillary acidic protein (GFAP) concentration as a diagnostic marker for canine central nervous system (CNS) disorders, sera from dogs with various CNS $(n=47)$ and non-CNS $(n=56)$ disorders were measured for GFAP by using an ELISA kit. Healthy Beagles $(\mathrm{n}=15)$ and Pug dogs $(\mathrm{n}=12)$ were also examined as controls. Interestingly, only Pug dogs with necrotizing meningoencephalitis (NME) showed elevated serum GFAP concentrations $(<0.01$ to $1.14 \mathrm{ng} / \mathrm{m} l)$, while other breeds of dogs with NME did not. Among the Pug dogs with NME, serum GFAP concentrations did not correlate with their clinical features, such as ages or survival times. Our data indicate the usefulness of serum GFAP as a novel marker for Pug dogs with NME.

KEY WORDS: canine, glial fibrillary acidic protein, necrotizing meningoencephalitis, serum.

doi: 10.1292/jvms.13-0252; J. Vet. Med. Sci. 75(11): 1543-1545, 2013

Necrotizing meningoencephalitis (NME), necrotizing leukoencephalitis (NLE) and granulomatous meningoencephalomyelitis (GME) are well-known idiopathic inflammatory diseases of the canine central nervous system (CNS). While the unique clinical and pathological features of these disorders have been well described by numerous reports $[6$, 7], poor information is available about laboratory tests that can help the premortem diagnosis.

We previously reported the high prevalence of autoantibodies against glial fibrillary acidic protein (GFAP) in the cerebrospinal fluid (CSF) in dogs with NME [4]. However, the CSF anti-GFAP autoantibodies were also detected in some dogs with GME and brain tumors. We also revealed the elevated GFAP concentrations in the CSF from Pug dogs with NME [8]. Although the GFAP concentrations in the CSF were negligibly low in CNS diseases other than NME, several healthy Pug dogs possessed elevated GFAP concentrations in their CSF. We have recognized the problem of these CSF tests, lacking disease specificity. In the present study, we examined the ability of serum GFAP concentrations as a specific marker for canine NME or any CNS disorder.

Forty-seven dogs with CNS disorders were included in this study. These dogs were referred to The University of Tokyo Veterinary Medical Center (UT-VMC) between 2001 and 2011. NME $(n=18), \operatorname{NLE}(n=5)$ and GME $(n=6)$ were diagnosed based on the signalment, clinical signs, magnetic resonance images (MRI), routine CSF tests and postmortem histopathology. All of 18 dogs with NME and one of 6 dogs

\footnotetext{
*Correspondence to: Matsuki, N., Department of Veterinary Clinical Pathobiology, Graduate School of Agricultural and Life Sciences, The University of Tokyo, 1-1-1 Yayoi, Bunkyo-ku, Tokyo 113-8657, Japan.

e-mail: amki@mail.ecc.u-tokyo.ac.jp

(C)2013 The Japanese Society of Veterinary Science
}

with GME were positive for anti-GFAP autoantibodies. Eighteen dogs with other CNS disorders, such as brain tumors, canine Distemper encephalitis, congenital hydrocephalus and idiopathic epilepsy, were also diagnosed by MRI, CSF tests, microbiological tests, electroencepharogram tests and/or postmortem examination. Blood sera were collected at the first admission. Sera from dogs with non-CNS diseases $(n=56)$ were randomly collected at the UT-VMC between 2011 and 2012. These dogs had various non-CNS disorders including neoplastic $(n=16)$, hematologic $(n=14)$, gastrointestinal $(n=8)$, hepatic $(n=4)$, orthopedic $(n=4)$, endocrine $(n=3)$, dermatologic $(n=2)$, renal $(n=1)$, circulatory $(n=1)$ or other $(\mathrm{n}=2)$ diseases diagnosed based on the clinical records. As healthy controls, fifteen adult Beagles and 12 Pug dogs that had no evidence of disease were included. All sera were stored at $-30^{\circ} \mathrm{C}$ before use in this study.

Serum GFAP concentrations were determined in duplicate by using a commercial ELISA kit for human GFAP (BioVendor Laboratory Medicine, Modrice, Czech). The cross reactivities of anti-GFAP antibodies in the kit with canine GFAP were confirmed by an indirect immunofluorescence assay by using cultured canine astrocytes (data not shown). ELISA data were statistically evaluated by a Kruskal-Wallis test followed by Dunn's test using GraphPad Prism 5 for Macintosh OS (La Jolla, CA, U.S.A.). Statistical significance was assigned at $P<0.05$.

Figure 1 shows serum GFAP concentrations of all dogs included in this study. Only Pug dogs with NME showed elevated serum GFAP concentrations, that were significantly higher than 4 Chihuahuas and 2 Shi-tzus with NME $(P<0.05)$, dogs with other CNS diseases $(P<0.001)$, dogs with nonCNS diseases $(P<0.001)$ and the healthy controls $(P<0.001)$. When the cut-off value of serum GFAP was set at $0.1 \mathrm{ng} / \mathrm{ml}$, the sensitivity and specificity in Pug dogs with NME were $67 \%$ and $100 \%$, respectively. In this study, we included two healthy Pug dogs that showed elevated GFAP concentrations 


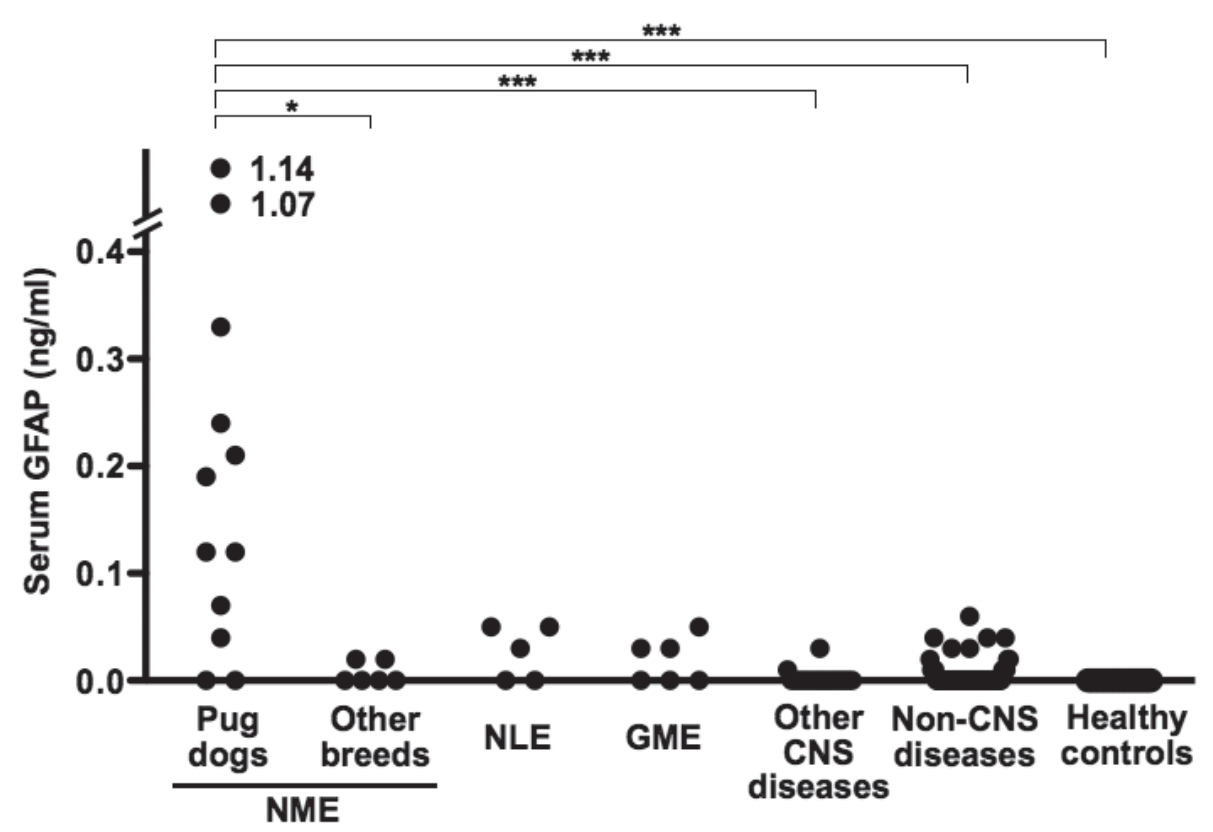

Fig. 1. Serum glial fibrillary acidic protein (GFAP) concentrations in Pug dogs and other breeds of dogs with necrotizing meningoencephalitis (NME), dogs with necrotizing leukoencephalitis (NLE), dogs with granulomatous meningoencephalomyelitis (GME), dogs with other CNS diseases, dogs with non-CNS diseases and healthy controls $(* P<0.05$, ***P<0.001. Dunn's test).

Table 1. Ages at onset, gender, durations from disease onset to examination, treatment before examination, survival times from onset and serum glial fibrillary acidic protein (GFAP) concentrations of 12 Pugs with necrotizing meningoencephalitis

\begin{tabular}{ccccccc}
\hline No. & Age & Gender ${ }^{\text {a) }}$ & $\begin{array}{c}\text { Duration from onset to } \\
\text { examination (month) }\end{array}$ & $\begin{array}{c}\text { Treatment before } \\
\text { examination }^{\text {b }}\end{array}$ & $\begin{array}{c}\text { Survival time } \\
(\text { month })\end{array}$ & $\begin{array}{c}\text { Serum GFAP } \\
(n \mathrm{~g} / \mathrm{m} l)\end{array}$ \\
\hline 1 & $1 \mathrm{Y} 6 \mathrm{M}$ & $\mathrm{F}$ & $<1 \mathrm{M}$ & $\mathrm{G}+\mathrm{P}$ & $<1 \mathrm{M}$ & $<0.01$ \\
2 & $4 \mathrm{Y} 8 \mathrm{M}$ & $\mathrm{NF}$ & $2 \mathrm{M}$ & $\mathrm{P}$ & $32 \mathrm{M}$ & $<0.01$ \\
3 & $1 \mathrm{Y} 3 \mathrm{M}$ & $\mathrm{NF}$ & $9 \mathrm{M}$ & $\mathrm{G}+\mathrm{P}+\mathrm{Z}$ & $16 \mathrm{M}$ & 0.04 \\
4 & $0 \mathrm{Y} 8 \mathrm{M}$ & $\mathrm{F}$ & $<1 \mathrm{M}$ & $\mathrm{G}+\mathrm{P}$ & $1 \mathrm{M}$ & 0.07 \\
5 & $6 \mathrm{Y} 2 \mathrm{M}$ & $\mathrm{F}$ & $1 \mathrm{M}$ & $\mathrm{P}$ & $2 \mathrm{M}$ & 0.12 \\
6 & $1 \mathrm{Y} 0 \mathrm{M}$ & $\mathrm{M}$ & $<1 \mathrm{M}$ & $\mathrm{P}$ & $<1 \mathrm{M}$ & 0.12 \\
7 & $6 \mathrm{Y} 0 \mathrm{M}$ & $\mathrm{NF}$ & $27 \mathrm{M}$ & $\mathrm{G}+\mathrm{P}$ & $31 \mathrm{M}$ & 0.19 \\
8 & $2 \mathrm{Y} 11 \mathrm{M}$ & $\mathrm{F}$ & $<1 \mathrm{M}$ & $\mathrm{G}+\mathrm{P}$ & $11 \mathrm{M}$ & 0.21 \\
9 & $2 \mathrm{Y} 5 \mathrm{M}$ & $\mathrm{NM}$ & $9 \mathrm{M}$ & $\mathrm{G}+\mathrm{D}$ & $29 \mathrm{M}$ & 0.24 \\
10 & $0 \mathrm{Y} 6 \mathrm{M}$ & $\mathrm{M}$ & $6 \mathrm{M}$ & - & $9 \mathrm{M}$ & 0.33 \\
11 & $2 \mathrm{Y} 1 \mathrm{M}$ & $\mathrm{F}$ & $<1 \mathrm{M}$ & $\mathrm{G}+\mathrm{P}$ & $13 \mathrm{M}$ & 1.07 \\
12 & $0 \mathrm{Y} 11 \mathrm{M}$ & $\mathrm{M}$ & $<1 \mathrm{M}$ & $\mathrm{G}$ & $<1 \mathrm{M}$ & 1.14 \\
\hline
\end{tabular}

a) M, NM, F and NF indicate male, neutered male, female and neutered female, respectively. b) G, P, Z and D indicate glucocorticoids, phenobarbital, zonisamide and diazepam, respectively.

in the CSF in our previous report [8]. Interestingly, the serum GFAP concentrations in these Pug dogs were under detection limit. Table 1 shows the clinical profiles and serum GFAP concentrations of 12 Pug dogs with NME. The ages at onset, gender, duration from onset to examination, treatment before examination or survival time from onset had no obvious relationship to the serum GFAP concentrations.

In the present study, we found the elevated serum GFAP concentrations that were highly specific for Pug dogs with NME. In humans, while elevated serum GFAP concentra- tions reflect intracerebral hemorrhage $[1,2]$, acute cerebral stroke $[1,10]$ and traumatic brain injury $[5,9]$, serum antiGFAP autoantibodies are quite rare. On the other hand, many of healthy and diseased dogs have circulating anti-GFAP autoantibodies [3]. Thus, we predicted that a small amount of GFAP leaked from the CNS would be captured or that the GFAP assay would be interfered by the autoantibodies.

From our previous and present studies, we can hypothesize the mechanism of elevated serum GFAP concentrations in Pug dogs with NME. There may be certain fragility of as- 
trocytes even in healthy Pug dogs that allows GFAP leakage into the CSF [8], and then when NME starts, GFAP moves into the circulation via the damaged blood-brain barrier. This phenomenon may not occur in other breeds of dogs with NME, suggesting the profound difference in the pathogenesis of NME between the Pug and other breeds.

In conclusion, although the present study deals with small numbers of dogs, serum GFAP may be used as a novel specific marker for NME in Pug dogs, that can be used in any disease stage. To increase the diagnostic sensitivity, some modifications to the ELISA may be necessary.

\section{REFERENCES}

1. Dvorak, F., Haberer, I., Sitzer, M. and Foerch, C. 2009. Characterisation of the diagnostic window of serum glial fibrillary acidic protein for the differentiation of intracerebral haemorrhage and ischaemic stroke. Cerebrovasc. Dis. 27: 37-41. [Medline] [CrossRef]

2. Foerch, C., Curdt, I., Yan, B., Dvorak, F., Hermans, M., Berkefeld, J., Raabe, A., Neumann-Haefelin, T., Steinmetz, H. and Sitzer, M. 2006. Serum glial fibrillary acidic protein as a biomarker for intracerebral haemorrhage in patients with acute stroke. J. Neurol. Neurosurg. Psychiatry 77: 181-184. [Medline] [CrossRef]

3. Fujiwara, K., Matsuki, N., Shibuya, M., Tamahara, S. and Ono, K. 2008. Autoantibodies against glial fibrillary acidic protein in canine sera. Vet. Rec. 162: 592-593. [Medline] [CrossRef]

4. Matsuki, N., Fujiwara, K., Tamahara, S., Uchida, K., Matsunaga, S., Nakayama, H., Doi, K., Ogawa, H. and Ono, K. 2004. Preva- lence of autoantibody in cerebrospinal fluids from dogs with various CNS diseases. J. Vet. Med. Sci. 66: 295-297. [Medline] [CrossRef]

5. Mondello, S., Papa, L., Buki, A., Bullock, M. R., Czeiter, E., Tortella, F. C., Wang, K. K. and Hayes, R. L. 2011. Neuronal and glial markers are differently associated with computed tomography findings and outcome in patients with severe traumatic brain injury: a case control study. Crit. Care 15: R156. [Medline] [CrossRef]

6. Park, E. S., Uchida, K. and Nakayama, H. 2012. Comprehensive immunohistochemical studies on canine necrotizing meningoencephalitis (NME), necrotizing leukoencephalitis (NLE), and granulomatous meningoencephalomyelitis (GME). Vet. Pathol. 49: 682-692. [Medline] [CrossRef]

7. Talarico, L. R. and Schatzberg, S. J. 2010. Idiopathic granulomatous and necrotising inflammatory disorders of the canine central nervous system: a review and future perspectives. J. Small Anim. Pract. 51: 138-149. [Medline] [CrossRef]

8. Toda, Y., Matsuki, N., Shibuya, M., Fujioka, I., Tamahara, S. and Ono, K. 2007. Glial fibrillary acidic protein (GFAP) and antiGFAP autoantibody in canine necrotising meningoencephalitis. Vet. Rec. 161: 261-264. [Medline] [CrossRef]

9. Vos, P. E., Jacobs, B., Andriessen, T. M., Lamers, K. J., Borm, G. F., Beems, T., Edwards, M., Rosmalen, C. F. and Vissers, J. L. 2010. GFAP and S100B are biomarkers of traumatic brain injury: an observational cohort study. Neurology 75: 1786-1793. [Medline] [CrossRef]

10. Wunderlich, M. T., Wallesch, C. W. and Goertler, M. 2006. Release of glial fibrillary acidic protein is related to the neurovascular status in acute ischemic stroke. Eur. J. Neurol. 13: 1118-1123. [Medline] [CrossRef] 